\title{
A New Methodology for Testing Spring Stiffness
}

\author{
Prathamesh D. Belapurkar ${ }^{1}$, Sushant. S. Jadhav ${ }^{2}$ \\ ${ }^{1}$ Final year B.E., Department of Mechanical, MES College of Engineering, Savitribai Phule Pune University - India \\ ${ }^{2}$ Assistant Professor, Department of Mechanical, MES College of Engineering, Savitribai Phule Pune University - India
}

\begin{abstract}
Mechanical Spring used in any machine has its own stiffness value. This stiffness value changes according to its application. A spring stiffness testing can be done using many methods like hydraulic actuators or by applying external load on the spring. Tested spring installed in a machine improves the performance of the machine and produces more efficient and reliable results. One of the method of testing spring stiffness is through its frequency. Only considering a single parameter i.e. (deflection due to vibration) stiffness of a spring can be calculated. Results are compared and on that basis modification and optimization of machine is done. This paper illustrates the application of new method of testing spring through its frequency and natural frequency to calculate their stiffness and deflection values.
\end{abstract}

Keywords: compression springs, spring frequency, spring stiffness, spring testing machine

\section{Introduction}

In today's world technology is upgrading drastically and it seems to be difficult to stay up to date with the changing scenario. Mechanical systems are being upgraded to electro-mechanical systems. Precision and accuracy is expected from every mechanical and electro-mechanical system. To achieve this precision and accuracy is a difficult task but it can be achieved by testing each and every component before its final assembly.

Mechanical spring is one of the component which needs to be tested before its final assembly. For any type of spring the most important factor is its stiffness value which differs according to its application. Springs are basically an elastic body which reacts according to the load applied i.e. tension or compression. Its purpose is to distort under load and absorb or release energy rapidly according it the respective condition. For coil springs, a typical performance test include applying a series of variable loads to each spring, literally bouncing it up and down for a specific period of time at a high rate of speed to determine its stiffness quantity [1]. These parameters are considered while testing springs. Rapid to and fro motion which produces vibrations leading to produce frequency is the principle used in designing and developing of this spring testing machine.

\section{Spring Stiffness Testing Machine}

"Spring testing machine are used for different purposes, this include SF1240 series spring testers which are commonly used to test stiffness of disc springs, ware springs, coil springs, and spring type components [1]." The Reference [4] shows the studies of the natural frequencies of helical springs. Propagation of elastic waves, sinusoidal excitation of the axial velocity with the help of analytical and numerical methods. As two different waves are propagated from spring, dynamic behavior of the strains were conducted. Hence depending on these tests carried, following are the considerations used in designing of the spring testing machine:

\section{A. Problem Definition}

Spring stiffness measurement consumes a lot of time and initial investment is also high which leads to high maintenance and operating cost. In industries as time is important parameter so is the accuracy of results which are obtained. Achieving the same precision and accuracy is difficult and time consuming. This machine is one of the method through which springs can be tested in an optimized cost and time.

\section{B. Working Principle}

Helical springs are the most commonly used springs in automotive industries. When they are used in applications which require motion, designer must be certain that the physical dimensions must not lead spring to produce resonating frequency due to the applied force, resulting into damping stresses, since the internal damping of spring is low [2]. According to the statement spring is not supposed to vibrate at its natural frequency hence it shouldn't be practiced. The resonating frequency should be greater than 15 to 20 times more to that of the frequency of the force or motion of the spring in order to avoid resonance with the harmonic frequency [2]. Hence, frequency lower than natural frequency should be practiced and is safe both for machine and spring. This concept is used for calculating the stiffness of spring.

A master spring is considered whose parameters like stiffness, natural frequency, material and dimensions are known. To start the testing frequency of the master spring is calculated using the spring testing machine. Note that this frequency is less than the natural frequency of master spring. Another spring which is made of the same material and same parameters but the stiffness value is unknown is considered. Using the same conditions frequency is calculated of the test spring. All parameters are kept constant like applied mass, length of spring, spring material, specific weight, outer and inner diameter of spring, wire diameter of spring, etc. Both the results are compared for accuracy and precision. And depending on this and the ratio obtained stiffness value of spring is calculated. 


\section{Mathematical Formulation}

The equation for the translational vibration of a spring is given as follows:

$$
\frac{\partial^{2} u}{\partial x^{2}}=\frac{W}{k g l^{2}} \frac{\partial^{2} u}{\partial t^{2}}
$$

Where

$$
\begin{aligned}
g & =\text { acceleration } \text { due to gravity } \\
\mathrm{k} & =\text { spring rate, } \mathrm{N} / \mathrm{mm} \\
\ell & =\text { length of spring, } \mathrm{mm} \\
W & =\text { weight of spring, } \mathrm{N} \\
\mathrm{x} & =\text { motion of any particle at distance } \mathrm{x}, \mathrm{mm}
\end{aligned}
$$

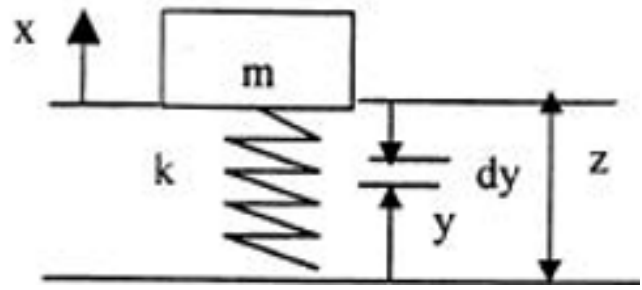

Figure 1: Spring Mass System
The harmonic equation depends upon the physical properties and the end conditions of the spring. The natural frequencies of spring between two flat parallel plates is given as

$$
\omega=m \pi \sqrt{\frac{k g}{W}} \mathrm{~m}=1,2,3, \ldots
$$

Where for $m=1$ the natural or fundamental frequency is found, similarly at $\mathrm{m}=2, \mathrm{~m}=3$, and so on. Since $\omega=2 \pi \mathrm{f}$ the fundamental frequency is given as

$$
f=\frac{1}{2} \sqrt{\frac{k g}{W}}, \mathrm{~m}=1
$$

In hertz, assuming both the spring ends are in contact with the plates. The weight of the active part of the spring is given as [2]

$$
W=A L \gamma=\frac{\pi^{2} d^{2} D N_{a} \gamma}{4}
$$

Where

$d=$ wire diameter, $\mathrm{mm}$

$\mathrm{D}=$ outer diameter of spring, $\mathrm{mm}$

$\mathrm{N}_{\mathrm{a}}=$ number of active turns

$\gamma=$ specific weight of spring, $\mathrm{N} / \mathrm{mm}^{3}$

Since the all parameters of master spring and test spring are kept constant the above equation can be converted into a compact basic equation. Where $\mathrm{W}, \mathrm{g}=$ constant, frequency is directly proportional to square root spring rate i.e.

$$
\begin{array}{r}
f \propto \sqrt{k} \\
f^{2}=c k \\
\frac{f^{2}}{k}=c=\text { constant ratio }
\end{array}
$$

Hence with the same equation natural frequency and spring can be calculated

$$
\frac{f_{n}^{2}}{k_{n}}=\frac{f^{2}}{k}=\mathrm{constant}
$$

Where

$$
\begin{aligned}
f_{n} & =\text { natural frequency of spring } \\
f & =\text { frequency lower than natural frequency } \\
k_{n} & =\text { spring rate at frequency } \mathrm{f}_{\mathrm{n}} \\
k & =\text { spring rate at frequency } \mathrm{f}
\end{aligned}
$$

Depending upon this ratio (8), natural frequency of the spring is calculated which will lead to spring stiffness.

\section{Construction and Operation of The Machine}

a) System Architecture

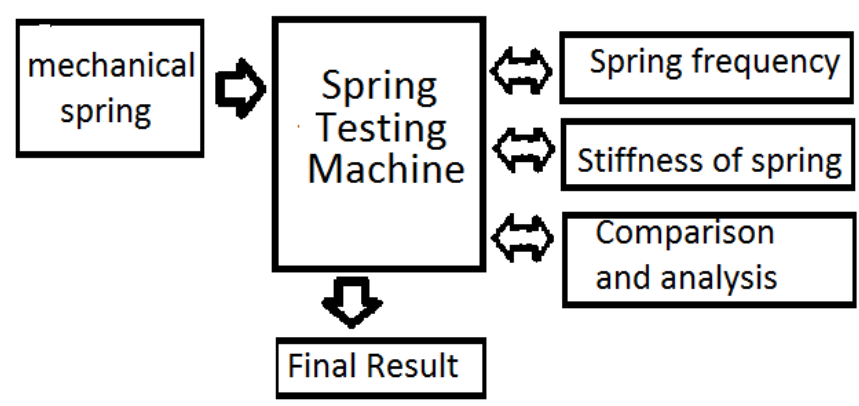

Figure 2: System Architecture

\section{b) Operation of the System}

The spring testing machine consists of two plates, two side pillars, a base, a mechanism which produces vibrations and a displacement sensor. The assembly consists of an upper plate and a lower plate. Spring is attached between these two plates. Upper plate is adjustable according to the height of spring and lower plate is connected to the vibrating mechanism. Some initial force is produced by the upper plate so that it can hold the spring between these two plates. When the force is applied on the spring by the upper plate, the lower plate is taken as the zeroth level. When the machine is started vibrating frequency is achieved which is less than natural frequency of the spring. Displacement sensors or vibrometers (amplitude measuring instruments) record the readings and are displayed on the screen. Minimum 4-5 readings are recorded to calculate the stiffness. This reduces the errors in the readings. Since natural frequency and stiffness of master spring is known the stiffness at a random frequency is calculated with the help of the machine. A ratio is obtained from these readings. Then the frequency at the same speed is calculated of the test spring and depending upon the ratio of master spring the stiffness value of spring is calculated.

\section{Tests and Results}

The tests carried out on various sizes of springs. Results of spring testing machine and universal testing machine were obtained. Comparison to calibrate the spring testing machine 


\section{International Journal of Science and Research (IJSR) \\ ISSN (Online): 2319-7064 \\ Index Copernicus Value (2013): 6.14 | Impact Factor (2014): 5.611}

resulted in few changes. Following results were obtained on both the machines:

$\mathrm{STM}=$ Spring testing machine

$\mathrm{UTM}=$ Universal testing machine

Table 1: Results of comparison of loads between STM and UTM

\begin{tabular}{|c|c|c|c|}
\hline $\begin{array}{c}\text { Extension } \\
(\mathrm{mm})\end{array}$ & $\begin{array}{c}\text { Force } \\
(\mathrm{kg})\end{array}$ & $\begin{array}{c}\text { Force } \\
(\mathrm{N}) \text { STM }\end{array}$ & $\begin{array}{c}\text { Force } \\
(\mathrm{N}) \text { UTM }\end{array}$ \\
\hline 0 & 0 & 0 & 0 \\
\hline 1 & 18.1 & 177.561 & 165 \\
\hline 2 & 46 & 454.203 & 435 \\
\hline 3 & 75.8 & 743.598 & 630 \\
\hline 4 & 104.3 & 1023.183 & 900 \\
\hline 5 & 132.9 & 1303.749 & 1177.5 \\
\hline 6 & 162.1 & 1590.201 & 1462.5 \\
\hline 7 & 190.8 & 1871.748 & 1755 \\
\hline 8 & 221.4 & 2171.934 & 2047.5 \\
\hline 9 & 252.6 & 2478.006 & 2340 \\
\hline 10 & 283.7 & 2783.097 & 2647.5 \\
\hline 11 & 316.5 & 3104.865 & 2955 \\
\hline 12 & 350 & 3441.348 & 3270 \\
\hline 13 & 384.8 & 3774.888 & 3577.5 \\
\hline 14 & 421.4 & 4133.934 & 3892.5 \\
\hline 15 & 458.1 & 4493.961 & 4207.5 \\
\hline 16 & 496.1 & 4866.741 & 4530 \\
\hline 17 & 534.8 & 5246.388 & 4852.5 \\
\hline 18 & 573.2 & 5623.092 & 5182.5 \\
\hline 19 & 610.8 & 5991.948 & 5505 \\
\hline 20 & 650.6 & 6382.386 & 5820 \\
\hline & & & \\
\end{tabular}

The above readings shows significant increase in the difference between these two machines. After plotting a graph a gradual increase in difference were calculated. Due to these results modifications in fixtures will be done for more accurate results. Following is the graph which shows these results in a more precise form.

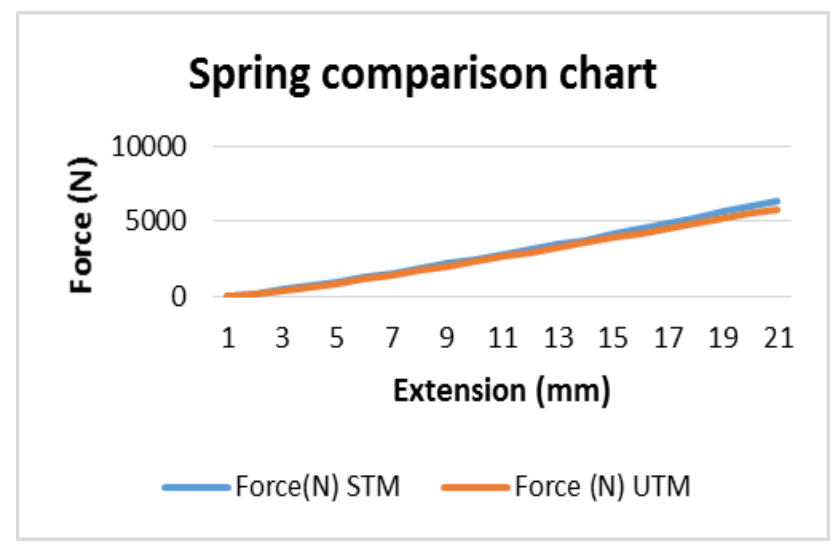

Figure 3: comparison graph between STM and UTM

Fig (3) shows a graph of comparison between spring testing machine and universal testing machine. It shows that both the readings have a similarities, but as the weight and extension increases there is a consecutive increase in their difference.

\section{Conclusion}

For each spring stiffness is the most important performance characteristics. The result collected were compared with a master spring readings and according to that necessary changes will be done to the machine. Basically testing carries a comparison which contain tolerances. Springs are accepted or rejected on precise data analysis. The above results give precise results. The results obtained were on average $93.01 \%$ accurate with reference to Universal testing machine. Slight improvement is required as far as industrial tolerance standards are concerned. The results obtained were significantly precise and consistent.

\section{Future Scope}

a) Fatigue Testing Machine

Fatigue Testing Machine is one of the machine which uses this type of process to calculate the fatigue life of the spring. As in industries two machines are required, spring testing machine and fatigue testing machine. Both the concept can be applied to a same machine to reduce initial and operating cost of a machine.

\section{b) Improvement in Fixtures}

Significant improvement can be done by adding necessary fixtures or dampers to reduce errors and the force applied. With such efforts accurate and precise results can be obtained. But as the machine does its work of precise results same is expected by the spring. Spring material is also important as far as testing machine is concerned. Machine shouldn't ware out due to excessive use of spring. Depending on the required operating conditions and design, any material can be used to construct a spring, so the material has the required combination of rigidity and elasticity [3]. Hence machine is also designed depending on the applications and material used.

\section{c) Application of concept}

Frequency of any component in a machine is different. Depending on the size, shape and material used frequency changes. This concept of frequency is old and can be applied to almost all components. As frequency of all components differs, stiffness differ too. Hence frequency of these components should be used to design and improve the life of the components. Hence more in-depth study of this concept is required.

\section{References}

[1] O. O. Ayodeji, M. S. Abolarin, J. J. Yisa, A. G. Muftau and A. C. Kehinde, "Design and construction of a spring stiffness testing machine," AJER Trans, vol. 4, pp. 79-84, April 2015

[2] R. G. Budynas and J. K. Nisbett "Shigley's Mechanical engineering design," McGraw Hill Publication, $9^{\text {th }}$ Edition. 2011.

[3] https://en.wikipedia.org/wiki/Spring_\%28device\%29

[4] A. Hamza, S. Ayadi, E. Hadj-Taieb, "The natural frequencies of waves in helical springs," sci.direct 341(2013) 672-686 oct 2013

\section{Volume 4 Issue 12, December 2015}

